\title{
UMA ATIVIDADE DE CAMPO NO SANTUÁRIO DO LIMA/RN: PROPOSTA DE ATIVIDADE DE GEOMETRIA
}

\author{
A FIELD ACTIVITY IN THE SANTUÁRIO DO LIMA/RN: PROPOSAL FOR A \\ GEOMETRY ACTIVITY
}

DOI: $\underline{10.23926 / R P D .2526-2149.2020 . v 5 . n 2 . p 700-722 . i d 782 ~}$

\section{Nayara Alves Gomes \\ Mestre em Ensino (UERN) \\ nayarasjp44@gmail.com}

\section{Glaydson Francisco Barros de Oliveira \\ Doutor em Física (UFC) \\ Professor na Universidade \\ Federal Rural do Semi-Árido \\ (UFERSA) \\ glaydson.barros@ufersa.edu. $\underline{\mathrm{br}}$}

Resumo: Este artigo apresenta um recorte de uma pesquisa de mestrado, em que propomos uma atividade de campo como metodologia para o ensino de conceitos geométricos em conjunto com a resolução de situações-problemas. A pesquisa foi realizada com alunos do $9^{\circ}$ ano do Ensino Fundamental, desenvolvida a partir da aplicação de uma sequência didática, dividida em três etapas. $\mathrm{Na}$ primeira etapa, foram ministrados os conceitos geométricos necessários para o desenvolvimento da atividade de campo. $\mathrm{Na}$ segunda etapa, foi realizada a atividade de campo no Santuário do Lima, durante a qual os alunos resolveram situações-problemas préelaboradas. $\mathrm{Na}$ terceira etapa, foi realizada avaliação da aprendizagem. Com a realização da atividade de campo, os alunos puderam observar e identificar conceitos geométricos presentes nas edificações do Santuário. A promoção de uma Educação Matemática crítica, em ambiente não formal, pôde colaborar com a formação de alunos mais reflexivos e capazes de dar significados aos conceitos em sua realidade.

Palavras-chave: Atividade de campo. Conceitos geométricos. Situações-problemas. Sequência didática. Santuário do Lima.

\begin{abstract}
This article presents a master's research process that proposes a field activity as a methodology for the teaching of geometric concepts linked with problem situations. Was carried with students from the 9th grade of elementary, developed from the application of a didactic sequence, divided into three stages. In the first stage, the geometric concepts necessary for the development of the field activity were taught. In the second stage, the field activity was carried out at the Santuário do Lima, where the students solved pre-elaborated problem situations. In the third stage, learning assessment was carried out. Because of the application of the field activity, the students were able to observe and identify geometric concepts present in the buildings of the Santuário. The promotion of critical Mathematics Education, in a non-formal environment was able to collaborate with the formation of reflective students capable of giving meanings to concepts in their reality.
\end{abstract}

Keywords: Field activity. Geometric concepts. Problem situations. Didactic sequence. Santuário do Lima. 


\section{INTRODUÇÃO}

Frequentemente, os alunos associam os problemas de matemática ao inimaginável, caracterizando-os como difíceis de serem resolvidos ou impalpáveis daquilo que está presente em seu contexto. Esses pensamentos podem levá-los a desgostar da disciplina e acreditar que não conseguem aprender seus conteúdos, como é visto diante dos conceitos geométricos. Com intuito de amenizar essas ideias, é importante que façamos uso de estratégias e metodologias de ensino que possibilitem o aluno enxergar a matemática como algo que é possível aprender, que essas metodologias sejam contextualizadas a partir do contexto dos alunos. Podemos destacar como metodologias para o ensino de matemática bem como para o ensino de geometria, a atividade de campo e a resolução de situações-problemas. O estudo de geometria pode ser aprofundado a partir de uma atividade de campo, pois "pode constituir uma excelente alternativa metodológica que permite explorar múltiplas possibilidades de aprendizagem dos alunos, desde que bem planejada e elaborada" (VIVEIRO; DINIZ, 2009, p. 27). Possibilita fazer ligação entre conteúdo e sua aplicabilidade a partir da observação das formas presentes em determinado local, desde seu projeto arquitetônico à construção do seu entorno.

Trabalhar com a resolução de problemas faz com que as aulas sejam dinâmicas e atrativas, contribuindo para que os alunos obtenham uma aprendizagem significativa. Por meio dela, os alunos podem utilizar seus próprios conhecimentos para alcançar estratégias que permitem chegar à resolução e assim, possam aprender novos conceitos (CARDOZO; MENEGHELLI; POSSAMAI, 2018). Assim, nossa pesquisa partiu da seguinte questão norteadora: a utilização da atividade de campo e a resolução de situações-problemas como metodologias para o ensino de matemática, podem contribuir para aprendizagem de conceitos geométricos? Nosso intuito é de promover melhorias na aprendizagem dos alunos e abrir possibilidades para modificações na prática docente, em que o professor esteja empenhado a buscar metodologias que impulsionem os alunos a participarem ativamente das aulas. Com isso, fomos motivados a realizar esta pesquisa.

Diante da potencialidade em ministrar aulas embasadas nessas metodologias, a pesquisa teve como objetivo geral, realizar uma atividade de campo para observar e identificar conceitos geométricos, presentes nas edificações do Santuário de Nossa Senhora dos Impossíveis, localizado no Estado do Rio Grande do Norte, implementada por situações-problemas préelaboradas a partir da observação de aspectos arquitetônicos presentes nas edificações do Santuário. Para atingir o objetivo geral, propomos:

- Uma atividade de campo visando a interdisciplinaridade; 
- Atividade de identificação de formas geométricas presentes na edificação do Santuário de Nossa Senhora dos Impossíveis - RN;

- Situações-problemas associadas à arquitetura do Santuário;

- Relacionar o conteúdo estudado no livro didático com as formas observadas nos espaços visitados;

Assim, podemos dar sentido às aulas e os conteúdos estudados, permitindo novos olhares dos alunos a respeito da disciplina, bem como promover a curiosidade dos alunos e o desejo de solucionar diversos outros problemas, possibilitando que professores não se mantenham presos ao espaço físico da escola.

É fato que "a Matemática se caracteriza como uma forma de compreender e atuar no mundo e o conhecimento gerado nessa área do saber como um fruto da construção humana na sua interação constante com o contexto natural, social e cultural” (BRASIL, 1998, p. 24). A atividade de campo mostra-se como uma metodologia viável, que pode ser utilizada durante as aulas de matemática, possibilitando aos alunos uma experiência enriquecedora, que os permite observar, relacionar e aprofundar os conhecimentos matemáticos, antes vistos apenas em sala de aula.

Uma atividade de campo permite que "o aluno se sinta protagonista de seu ensino, que é um elemento ativo e não um mero receptor de conhecimento" (DE FRUTOS et al., 1996, p. 15). Possibilita ainda que os alunos estejam instigados a estudar a disciplina e obter bons resultados, "as atividades de campo permitem o contato direto com o ambiente, possibilitando que o estudante se envolva e interaja em situações reais, confrontando teoria e prática, além de estimular a curiosidade e aguçar os sentidos" (VIVEIRO; DINIZ, 2009, p. 29). Através dela os alunos podem perceber que as formas que estão ao seu redor, podem ser olhadas e estudadas a partir de conhecimentos matemáticos, o que permite fazer a relação entre os conteúdos que são vistos em sala de aula e com tudo o que tem disponível além dela. Diante da importância da utilização de atividades de campo como forma de facilitar a aprendizagem dos alunos, Carbonell (2002) enfatiza que os espaços além da sala de aula são estimulantes, e quando bem aproveitados, são relevantes e tornam-se excelentes cenários que favorecem a aprendizagem. Segundo Hansen (2013), por meio da curiosidade, a criança desenvolve a capacidade de agir, observar e explorar o que está ao seu redor, o que justifica a necessidade de orientações para se ter uma aprendizagem significativa, efetiva para o desenvolvimento cognitivo, afetivo, psicomotor e social da criança. 
A resolução de situações-problemas pode ser considerada como uma metodologia significante para o ensino de matemática, pois permite desenvolver atividades relacionadas com a aplicabilidade da matemática, mostrar diversas situações e contextos em que ela pode ser observada, possibilitando que os alunos se tornem o centro do processo educacional, em que passa a ser ativo e influencia diretamente na construção do seu conhecimento. Assim, durante as aulas de matemática é importante que seja implementado no processo de ensino,

\begin{abstract}
[...] situações em que o aluno deva ser criativo, ou onde o aluno esteja motivado a solucionar um problema pela curiosidade criada pela situação em si ou pelo próprio desafio do problema. Na matemática escolar o aluno não vivencia situações de investigação, exploração e descobrimento. O processo de pesquisa matemática é reservado a poucos indivíduos que assumem a matemática como seu objeto de pesquisa. É esse processo de pesquisa que permite e incentiva a criatividade ao se trabalhar com situações problemas. (D’AMBRÓSIO, 1989, p. 16).
\end{abstract}

São problemas que trazem por trás de seu contexto situações que instigam os alunos a solucioná-los, o que proporciona ser criativos e flexíveis durante a resolução, podendo ser denominados como situações-problemas. Para Carvalho (2011, p. 82) "um problema é uma situação onde ocorre um desequilíbrio, ou seja, que exige uma solução não imediata, mas para a qual dispomos de meios intelectuais de resolução". É visto como algo que coloca o aluno a pensar e traçar caminhos para chegar à solução.

Trabalhar com a resolução de situações-problemas nas aulas de matemática mostra-se como uma importante metodologia e substancial para a aprendizagem dos alunos. Segundo Dante (1989), “a resolução de problemas pode auxiliar e bastante no desenvolvimento de habilidades do educando, utilizando situações-problemas poderemos envolvê-lo e desafiá-lo a ponto de incentivá-lo, para que dessa forma lhe proporcione o pensamento produtivo" (DANTE, 1989, p. 11). Para que o aluno se sinta atraído a resolver um problema, ele deve ser motivador e desenvolver nele a curiosidade de obter as soluções. Segundo Echeverría e Pozo (1998), para que os alunos tomem as atividades escolares como "verdadeiros problemas" é preciso que tenham ligação com o seu contexto, contextos que sejam interessantes para eles. Para fazer essa relação com o contexto do aluno é de grande valia trabalhar com problemas que façam uso de aplicações matemáticas, assim, eles podem visualizar que a matemática está aplicada em diversos meios, além do ambiente escolar.

\title{
2 Metodologia
}

A pesquisa propôs a aplicação de uma Sequência Didática (SD) para o ensino de conceitos geométricos. Segundo Araújo (2013, p. 323), uma sequência didática "(doravante SD) é um modo de o professor organizar as atividades de ensino em função de núcleos temáticos 
e procedimentais". A pesquisa está alicerçada na atividade de campo e na utilização de situações-problemas pré-elaboradas, como forma de diminuir as dificuldades dos alunos e propiciar melhorias na aprendizagem de conceitos geométricos, ao mesmo tempo que possibilita complementar e fortalecer a compreensão desses conteúdos, antes visto em sala de aula. A pesquisa é caracterizada como qualitativa, pois o significado das coisas torna-se uma preocupação essencial (BOGDAN; BIKLEN, 1994), se fundamentando nas premissas da pesquisa-ação crítica e colaborativa, de modo a encurtar a ponte que separa a teoria da prática (THIOLLENT, 2011). Uma pesquisa-ação procura trabalhar com os sujeitos da pesquisa considerando-os colaboradores do processo de investigação (ELLIOTT, 2004), compreendendo a intervenção por parte do professor colaborador.

A proposta de ensino foi desenvolvida no ano de 2019 com 30 alunos do $9^{\circ}$ ano do Ensino Fundamental de uma escola pública, localizada na região Oeste do estado do Rio Grande do Norte. As ações desenvolvidas na pesquisa foram divididas em três etapas, sintetizadas na Figura 1. A primeira etapa foi alicerçada em atividades teóricas realizadas, exclusivamente, pelo professor titular da disciplina de matemática da escola escolhida, localizada na cidade de Almino Afonso/RN, próximo a cidade de Patu/RN. A segunda etapa foi desenvolvida com atividades práticas de campo, através da visita ao Santuário de Nossa Senhora dos Impossíveis, localizado na Serra do Lima, em Patu/RN. As intervenções pedagógicas desta etapa foram realizadas pelo professor, aqui caracterizado como colaborador, e pela pesquisadora. Vale destacar que o professor colaborador não realizou atividade de campo com a turma escolhida antes da aplicação da pesquisa. A terceira etapa consiste na avaliação da aprendizagem dos alunos, novamente em ambiente formal, através de uma atividade composta por situaçõesproblemas, elaboradas com dados obtidos a partir da visita ao próprio Santuário ou através de um relatório, descrevendo suas experiências da atividade de campo, com finalidade de averiguar melhorias na aprendizagem dos alunos que participaram da segunda etapa:

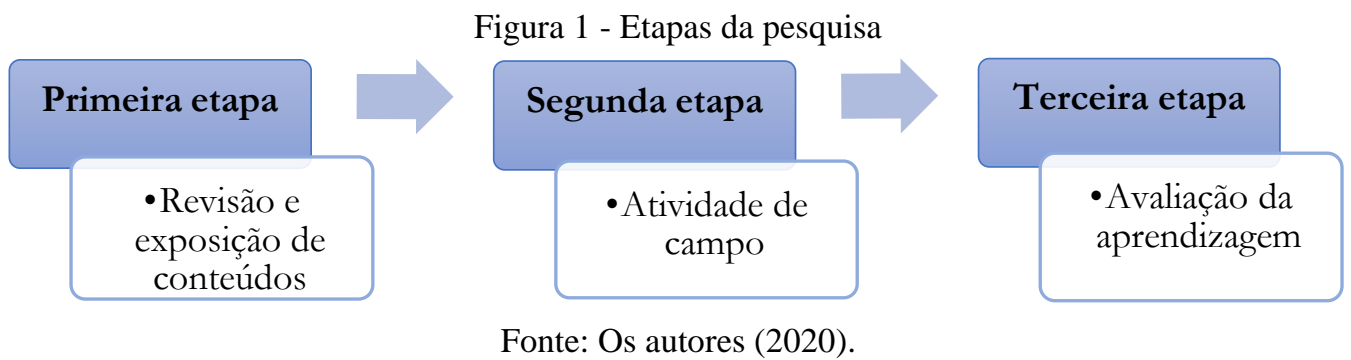

Ao todo, foram necessárias 13 horas/aulas (h/a) para o desenvolvimento da pesquisa, sendo destinadas $7 \mathrm{~h} / \mathrm{a}$ para a primeira etapa, $4 \mathrm{~h} / \mathrm{a}$ para a segunda etapa e $2 \mathrm{~h} / \mathrm{a}$ para a realização 
da terceira etapa. A aplicação da SD seguiu a seguinte cronologia de atividades teóricas e práticas, sendo apresentada no Quadro 1 ações de forma descritiva.

Quadro 1 - Intervenção Pedagógica Teórica e Prática da SD

\begin{tabular}{|c|c|l|l|l|}
\hline Etapas & $\begin{array}{l}\text { Horas/ } \\
\text { Aulas }\end{array}$ & \multicolumn{1}{|c|}{ Conteúdos } & Recursos didáticos & Objetivos de aprendizagem \\
\hline $\mathbf{1}^{\mathbf{a}}$ & $\mathbf{7}$ & $\begin{array}{l}\text { Polígonos e perímetro de } \\
\text { um polígono, área das } \\
\text { figuras geométricas } \\
\text { planas, sólidos } \\
\text { geométricos, } \\
\text { circunferência e círculo. }\end{array}$ & $\begin{array}{l}\text { Aula expositiva com } \\
\text { uso de lousa e pincel. }\end{array}$ & $\begin{array}{l}\text { Complementar os } \\
\text { conhecimentos geométricos; } \\
\text { facilitar a identificação e } \\
\text { classificação das figuras } \\
\text { planas. }\end{array}$ \\
\hline $\mathbf{2}^{\mathbf{a}}$ & $\mathbf{4}$ & $\begin{array}{l}\text { Transformação das } \\
\text { unidades de medida de } \\
\text { comprimento, polígonos, } \\
\text { identificação de figuras } \\
\text { geométricas planas e } \\
\text { sólidos geométricos, área } \\
\text { das figuras geométricas } \\
\text { planas, comprimento da } \\
\text { circunferência e área do } \\
\text { círculo. }\end{array}$ & $\begin{array}{l}\text { Atividade prática no } \\
\text { Santuário do Lima/RN } \\
\text { com utilização de } \\
\text { trena, corda, folha A4, } \\
\text { lápis, borracha e } \\
\text { celular. }\end{array}$ & $\begin{array}{l}\text { Identificar figuras } \\
\text { geométricas planas e sólidos } \\
\text { geométricos nas estruturas } \\
\text { arquitetônicas que compõem } \\
\text { o Santuário do Lima e seu } \\
\text { entorno; calcular área de } \\
\text { figuras geométricas planas } \\
\text { com dados coletados no } \\
\text { Santuário e área do círculo; } \\
\text { discutir os conhecimentos } \\
\text { geométricos aplicados no } \\
\text { Santuário. }\end{array}$ \\
\hline \multirow{2}{*}{} & $\mathbf{2}$ & $\begin{array}{l}\text { Comprimento da } \\
\text { circunferência, área do } \\
\text { círculo e área de figuras } \\
\text { geométricas planas. }\end{array}$ & $\begin{array}{l}\text { Folha A4 para } \\
\text { impressão das } \\
\text { situações-problemas } \\
\text { utilizadas na avaliação } \\
\text { da aprendizagem. }\end{array}$ & $\begin{array}{l}\text { Utilizar os dados coletados no } \\
\text { Santuário para solucionar } \\
\text { situações-problemas; ampliar } \\
\text { a compreensão acerca dos } \\
\text { conhecimentos geométricos. }\end{array}$ \\
\hline
\end{tabular}

Fonte: Os autores (2020).

\section{Resultados E Discussão}

$\mathrm{Na}$ primeira etapa da SD foram verificados, durante uma revisão dos conceitos geométricos, os conhecimentos que os alunos possuíam acerca dos conteúdos programados para serem vistos ao longo dos anos finais do Ensino Fundamental, necessários para o desenvolvimento das próximas etapas, como polígonos e perímetro de um polígono, área das figuras geométricas planas e identificação de sólidos geométricos, pois partimos do pressuposto que os alunos já tenham visto esses conteúdos em algum momento da sua vida escolar, por se tratarem de alunos do $9^{\circ}$ ano. Além da revisão, foi feito a exposição dos conteúdos programáticos da turma escolhida, como circunferência e círculo, abordados no livro didático da turma escolhida (SOUZA; PATARO, 2015). As intervenções desenvolvidas nesta etapa foram realizadas pelo professor colaborador, que ministrou os conteúdos durante suas aulas, utilizando o método tradicional de ensino, por meio de aula expositiva com utilização de lousa e pincel. 
Com a revisão, objetivamos amenizar as dificuldades dos alunos sobre os conteúdos considerados por nós como fundamentais para a continuação da pesquisa, nivelando os conhecimentos necessários e, a partir dos conteúdos programáticos que foram ministrados, favorecer novos conhecimentos a turma.

A segunda etapa foi realizada em espaço não-convencional, segundo Xavier e Fernandes (2008), durante a qual os alunos puderam resolver situações-problemas (SP) pré-elaboradas, com questões concretas sob o alcance visual de todos. A princípio, foi realizada uma visita com bastante antecedência ao Santuário, com o intuito de planejar e elaborar um roteiro para a atividade de campo. Foram analisadas todas as potencialidades para o ensino de geometria, presentes ao longo do percurso, até a parte central do Templo.

Após o consentimento dos pais acerca da participação dos alunos na atividade aqui proposta, deslocamo-nos ao local para a realização da aula. Para promover uma maior dinamicidade e um espírito de colaboração, os 19 alunos que participaram desta etapa foram distribuídos em 6 equipes, sendo cinco com 3 alunos e uma com 4 alunos. Os materiais necessários para a realização da atividade proposta, foram: Caderno, lápis e borracha - para registrar informações referentes aos conhecimentos matemáticos que fossem observados; câmera fotográfica e celular - para registrar imagens; fitas métricas ou trenas - para efetuar as medições necessárias. De início, e para incentivar os alunos, foi requerido aos mesmos que identificassem e registrassem aspectos relacionados a geometria estudada em sala de aula. Para isso, o professor colaborador solicitou que percorressem o Santuário, para que pudessem identificar as formas geométricas presentes e investigar as aplicações dos conceitos estudados em sala de aula. No percurso também estavam inclusos o pórtico e a rampa principal de chegada já no topo, as paredes que delimitam o entorno do pátio de estacionamento que contam a história da criação do santuário, a Igreja de Nossa Senhora dos Impossíveis (Figura 2) e o pórtico de saída para a barragem.

Foram propostas aos alunos sete SP's durante a atividade de campo. Para análise dos dados, classificamos as respostas dos alunos em quatro categorias: Resposta Satisfatória - RS; Resposta Pouco Satisfatória - RPS; Resposta Insatisfatória - RI e Sem Resposta - SR. As 7 (sete) SP's e os critérios utilizados estão no Quadro 2. 
Figura 2 - Vista da entrada do Santuário a partir da rampa de acesso

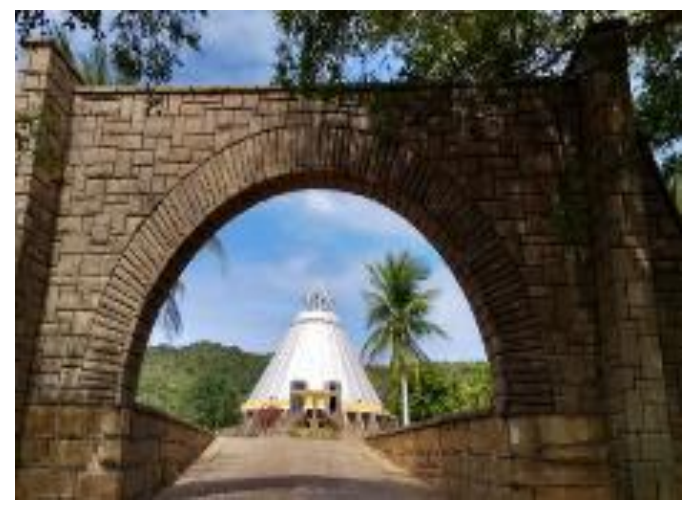

Fonte: Própria dos autores (2019).

Quadro 2 - SP's e Critérios para as Respostas

\begin{tabular}{|c|c|}
\hline Questões & Critérios \\
\hline Q1 & $\begin{array}{l}\text { RS: se abordasse o reconhecimento de polígonos, sólidos geométricos, circunferência e círculo } \\
\text { aplicados nas estruturas arquitetônicas do Santuário do Lima e no seu entorno; RPS: se } \\
\text { abordasse apenas uma tentativa de descrever os locais onde podem ser observados as aplicações } \\
\text { de polígonos, sólidos geométricos, circunferência e círculo, sem descrever quais foram os } \\
\text { conteúdos reconhecidos; RI: não abordasse os conhecimentos geométricos empregados nas } \\
\text { edificações do Santuário e no seu entorno. }\end{array}$ \\
\hline Q2 & $\begin{array}{l}\text { RS: se abordasse a área em } \mathrm{m}^{2} \text { do piso da capela do primeiro pavimento (térreo) do Santuário do } \\
\text { Lima, como é uma região circular, logo a área do círculo; RPS: se abordasse apenas como uma } \\
\text { tentativa de descrever a área em } \mathrm{m}^{2} \text { da capela do primeiro pavimento, onde o valor estimado para } \\
\text { o raio transcende o interior da capela; RI: não abordasse a área em } \mathrm{m}^{2} \text { da capela do primeiro } \\
\text { pavimento (área do círculo). }\end{array}$ \\
\hline Q3 & $\begin{array}{l}\text { RS: se abordasse as formas geométricas identificadas na estrutura apresentada na imagem da Q3 } \\
\text { e fosse estimado a área em } \mathrm{m}^{2} \text { da região destacada em vermelho na imagem (área do semicírculo } \\
+ \text { área do retângulo); RPS: se abordasse apenas como uma tentativa de descrever a área em } \mathrm{m}^{2} \\
\text { da região destacada em vermelho na imagem, no qual estimasse cada área separadamente e em } \\
\text { sequência não fossem somadas; RI: não abordasse a área em } \mathrm{m}^{2} \text { da região destacada em vermelho } \\
\text { na imagem. }\end{array}$ \\
\hline Q4 & $\begin{array}{l}\text { RS: se abordasse a área do assento de um dos bancos que pertence a estrutura que delimita o } \\
\text { Santuário do Lima e o número de lajotas quadradas de } 10 \mathrm{~cm} \text { de aresta necessárias para cobrir } \\
\text { seu assento; RPS: se abordasse apenas como uma tentativa de descrever o número de lajotas } \\
\text { quadradas necessárias para cobrir a superfície do banco, não efetuando a divisão da área total do } \\
\text { assento do banco pela área de cada lajota de } 10 \mathrm{~cm} \text { de aresta; RI: não abordasse a quantidade } \\
\text { correta de lajotas necessárias para cobrir o assento (superfície) de um dos bancos. }\end{array}$ \\
\hline Q5 & $\begin{array}{l}\text { RS: se abordasse a identificação de formas geométricas visualizadas no pórtico que dar acesso ao } \\
\text { Santuário do Lima e a área da região destacada na imagem da Q5 (triângulo); RPS: se abordasse } \\
\text { apenas como uma tentativa de descrever as formas geométricas identificadas e não calculasse a } \\
\text { área da região destacada; RI: não abordasse a área da região destacada na imagem da Q5 } \\
\text { (triângulo). }\end{array}$ \\
\hline Q6 & $\begin{array}{l}\text { RS: se abordasse a identificação de figuras geométricas na estrutura que dar sustentação ao } \\
\text { pavimento superior do Santuário (os pilares), um desenho de um desses pilares exemplificando } \\
\text { que se assemelham a um trapézio e a área da face de um dos pilares (área do trapézio); RPS: se } \\
\text { abordasse apenas como uma tentativa de descrever a área da face de um dos pilares (área do } \\
\text { trapézio) de forma que o resultado não seja satisfatório para os dados coletados; RI: não abordasse } \\
\text { os dados correspondente a estrutura de um dos pilares (as medidas do trapézio) e sua área. }\end{array}$ \\
\hline Q7 & $\begin{array}{l}\text { RS: se abordasse a quantidade de mudas que seriam plantadas ao longo do comprimento do } \\
\text { Santuário do Lima, em suas duas laterais; RPS: se abordasse apenas como uma tentativa de } \\
\text { descrever a quantidade de mudas considerando apenas uma das laterais; RI: não abordasse a } \\
\text { quantidade de mudas em nenhuma das laterais ou utilizasse a medida equivocada do comprimento } \\
\text { da praça que delimita o Santuário. }\end{array}$ \\
\hline
\end{tabular}

Fonte: Os autores (2020). 
Como demonstrado no quadro, as SP's e as soluções apresentadas pelos alunos podem ser vistas a seguir, bem como as análises decorrentes das soluções. Questão 1. No município de Patu-RN localiza-se o Santuário de Nossa Senhora dos Impossíveis, mais conhecido como Santuário do Lima, considerado uma das sete maravilhas do Rio Grande do Norte. O local encanta com sua beleza e arquitetura ímpar, grande parte da construção do Santuário é composta por pedras dispostas, estabelecendo ligações diretas com a matemática. Quais os possíveis conhecimentos geométricos empregados nas edificações do Santuário? Registre em seu caderno da forma que preferir.

Devido ao contexto subjetivo e bastante familiar dos alunos, na Q1 tivemos por parte das equipes respostas satisfatórias. Algumas das respostas apresentadas pelos alunos podem ser visualizadas no Quadro 3.

Quadro 3 - Respostas da questão 1 apresentadas pelos alunos

\begin{tabular}{|c|l|}
\hline Questão & \multicolumn{1}{c|}{ Respostas } \\
\hline \multirow{2}{*}{ Q1 } & "Retângulo, triângulo, cone, círculo" \\
\cline { 2 - 2 } & "Retângulos, cone, círculos, triângulo retângulo" \\
\cline { 2 - 2 } & "Retângulo, cone, círculo" \\
\cline { 2 - 2 } & $\begin{array}{l}\text { "No Santuário do Lima encontramos as seguintes formas: pirâmide, retângulo, quadrado, } \\
\text { triângulo, círculo, losango, triângulo retângulo e trapézio" }\end{array}$ \\
\hline
\end{tabular}

Fonte: Os autores (2020).

Questão 2. Ao chegar ao Santuário do Lima, a primeira visão é da Igreja de Nossa Senhora dos Impossíveis, que possui formato um tanto particular, e uma arquitetura que se destaca em Patu - RN. O Santuário está dividido em dois pavimentos, cada um possui uma capela. O primeiro pavimento (térreo), apresenta formato cilíndrico e o pavimento superior $\left(1^{\circ}\right.$ andar) em forma de um cone quando visto de fora do Santuário, ambos divididos pela mesma base circular. A base é o teto da capela do primeiro pavimento e o piso da capela do pavimento superior. Por possuir formato cilíndrico, a capela do primeiro pavimento também tem seu piso em formato circular. Supondo que futuramente seja preciso a renovação do piso da capela do primeiro pavimento, qual seria a quantidade $\mathrm{em}^{2}$ de piso necessário para cobrir essa região? Utilize fita métrica ou trena, para auxiliar na resolução. A figura a seguir faz referência à capela do primeiro pavimento. 
Figura 3 - Representação do piso da capela do primeiro pavimento

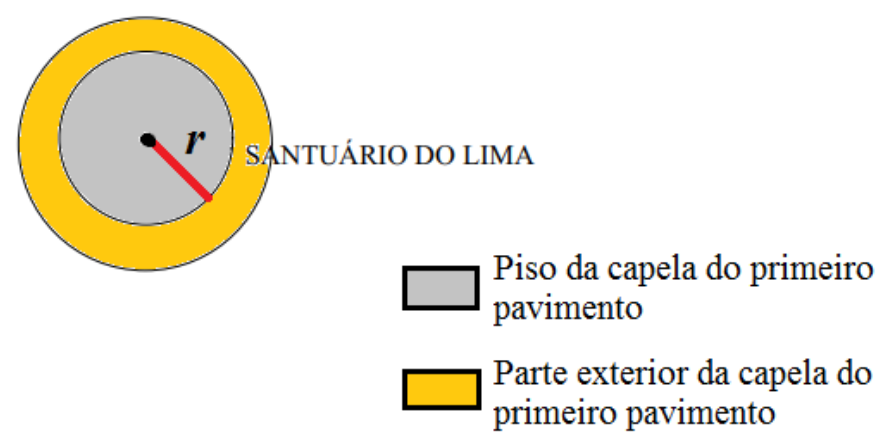

Fonte: Própria dos autores (2019).

As equipes obtiveram um bom desempenho na resolução da Q2, em que o maior número de respostas foi satisfatório, apresentadas por quatro equipes e apenas uma equipe teve sua resposta classificada como RPS. Seguem exemplos de respostas (Figura 4) em cada categoria onde houve ocorrência:

Figura 4 - (a) Resposta satisfatória a Q2; (b) Resposta pouco satisfatória a Q2

(a)

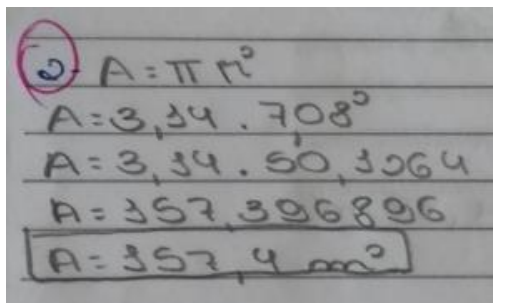

(b)

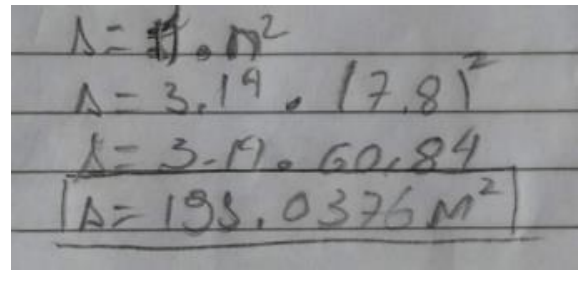

Fonte: Produção dos alunos (2019).

Diante da maior parte das respostas apresentadas, percebeu-se que os alunos tinham conhecimento sobre o cálculo da área do círculo. O processo de resolução da questão teve início durante medições que foram realizadas no piso da capela do primeiro pavimento, utilizando a trena com objetivo de estimar o valor do seu raio $(r=7,08 m)$. Durante a resolução da questão os alunos também utilizaram conhecimentos sobre transformações das unidades de medida de comprimento, quando fizeram conversões de centímetros para metros.

Questão 3. Ao longo da praça que cerca o Santuário do Lima, nas paredes que delimitam o pátio de estacionamento do Santuário, é possível notar a presença de diversos escritos em planos, com formatos que podem ser visualizados na figura abaixo. Para chegar ao último relato histórico da construção do novo Santuário em 1969, iniciamos o percurso pelo plano que contém o relato da doação de meia légua de terra feita pelo casal Abreu Ferreira e Paula Moreira Brito Pessoa e pelo Coronel Antônio Ferreira de Lima. Noutro plano, conhecemos o nome do primeiro administrador do Santuário, o Padre José Scholl. Assim, propomos: 
a) Procure na praça, a construção mostrada na figura abaixo, e identifique as formas geométricas contidas nessa estrutura; b) Considere que a região destacada em vermelho irá ser reformada e colocado novos azulejos no lugar, em toda parte composta pelos azulejos brancos e pelas pedras, como forma de renovar essa estrutura. Diante disso, quantos $\mathrm{m}^{2}$ serão ocupados pelos novos azulejos depois da reforma? Utilize fita métrica ou trena para auxiliar durante a resolução:

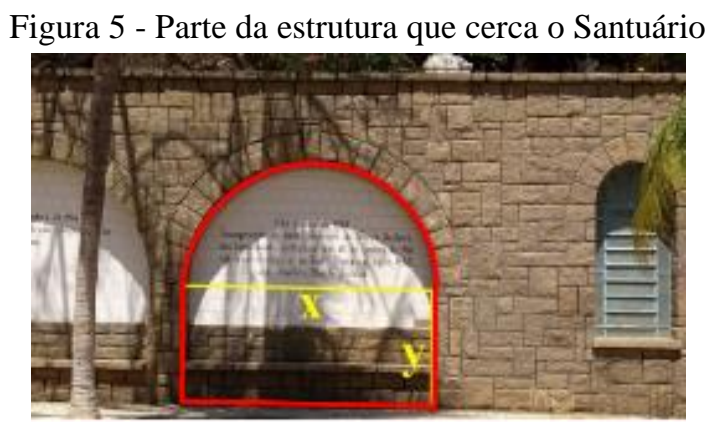

Fonte: própria dos autores (2019).

A terceira questão apresentou um nível de dificuldade um pouco mais elevado, apresentando respostas pouco satisfatórias (por três equipes) ou respostas insatisfatórias (duas equipes), além de não emergir nenhuma resposta satisfatória. A figura a seguir mostra exemplos das respostas nas categorias que ocorreram:

Figura 6 - (a) Resposta pouco satisfatória a Q3; (b) Resposta insatisfatória a Q3

(a)

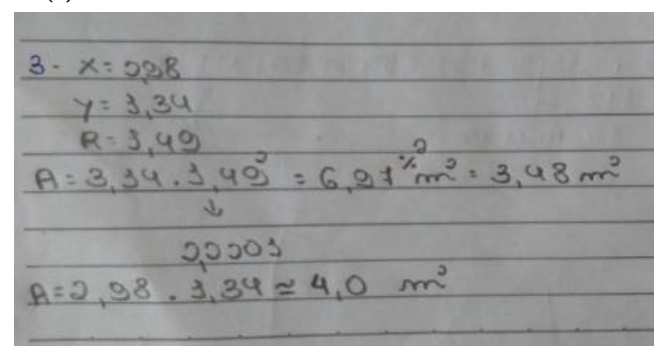

(b)

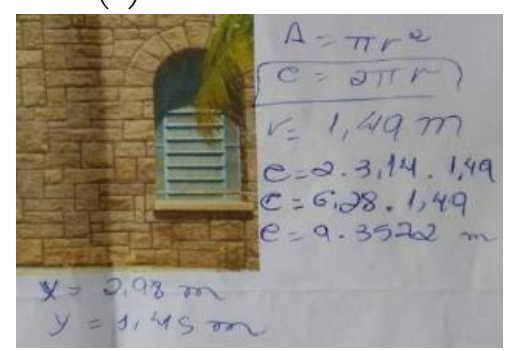

Fonte: Produção dos alunos (2019).

As equipes que tiveram suas respostas classificadas como RPS responderam de modo adequado a área de cada uma das formas geométricas separadamente, do retângulo e do semicírculo, mas por interpretação da situação, não acrescentaram na resolução, a área total (área do semicírculo + área do retângulo), ou seja, a área em $\mathrm{m}^{2}$ ocupada pelos novos azulejos após a reforma. Era aguardado a área total, como resultado 7,48 $\mathrm{m}^{2}$, aproximadamente. As respostas classificadas como RI não abordaram a área em $\mathrm{m}^{2}$ da região destacada em vermelho na imagem, ou então resolveram apenas uma das áreas das figuras geométricas, do retângulo ou do semicírculo. A Figura 6 (b), mostra a solução de uma equipe para a Q3, classificada como 
RI, em que foram estimadas as medidas e, ao invés de calcular a área do semicírculo, foi calculado o comprimento da circunferência, Além disso, a equipe não apresentou a área do retângulo.

Questão 4. Os bancos da praça são construídos por lajotas de pedras de variados tamanhos. Com o auxílio de um instrumento de medição, registre um padrão entre as medidas desses bancos. Também escolha um dos bancos para estimar a área do seu assento. Logo após, descubra o número máximo de lajotas quadradas de $10 \mathrm{~cm}$ de aresta que devem ser utilizadas para compor um assento como esse:

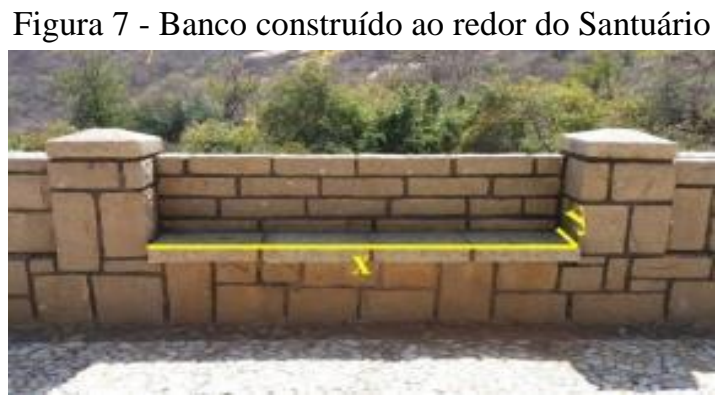

Fonte: Própria dos autores (2019).

As respostas da Q4 foram distribuídas em respostas satisfatórias, apresentadas por duas equipes, respostas insatisfatórias, também por duas equipes e uma equipe não apresentou resposta. A Figura 8 mostra os resultados obtidos por uma equipe, em que os cálculos realizados foram satisfatórios. Os alunos estimaram $X=197 \mathrm{~cm}$ e $Y=32 \mathrm{~cm}$, de acordo com essas medidas os resultados obtidos foram:

Figura 8 - Resposta satisfatória a Q4

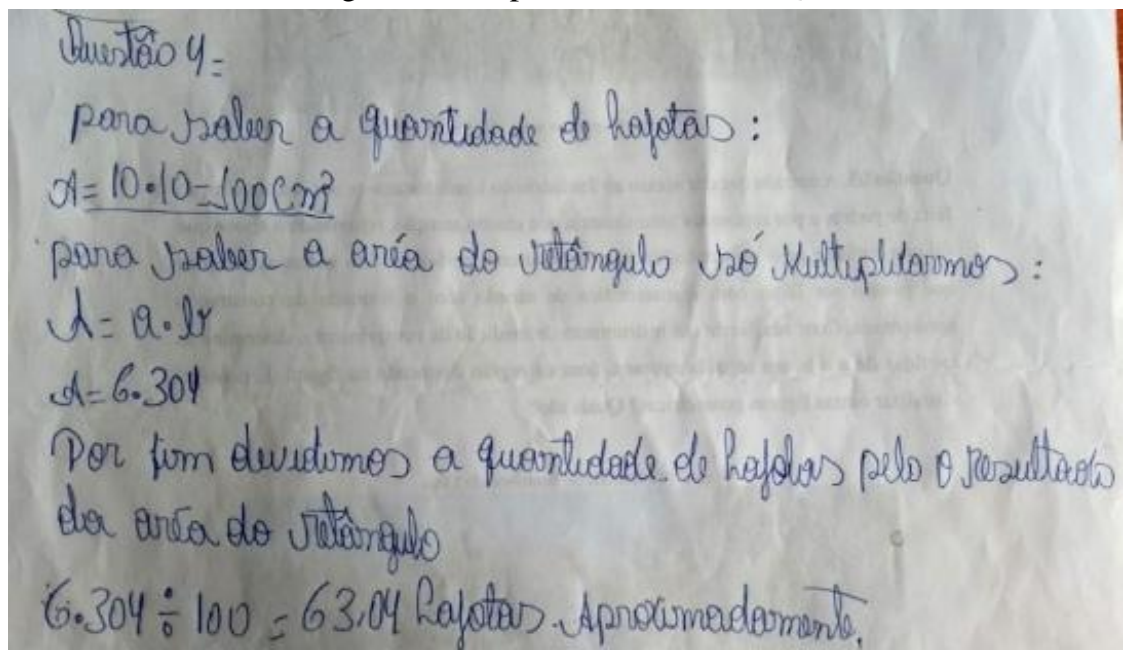

Fonte: Produção dos alunos (2019).

Durante a explicação dos cálculos efetuados, percebemos que a equipe não expôs suas ideias, de modo que houvesse conformidade com o desenvolvimento dos cálculos, embora os 
cálculos realizados sejam correspondentes com o que é solicitado, demonstrando entendimento acerca dos conteúdos explorados na situação. A resposta apresentada foi considerada como satisfatória, pois na resolução a equipe mostrou compreensão da situação e conteúdo abordado.

Nesse sentido, a Figura 9 mostra uma resposta de uma das equipes, classificada como insatisfatória para a Q4, pois durante a resolução, não é abordado a quantidade correta de lajotas necessárias para cobrir o assento (superfície) de um dos bancos.

Figura 9 - Resposta insatisfatória a Q4

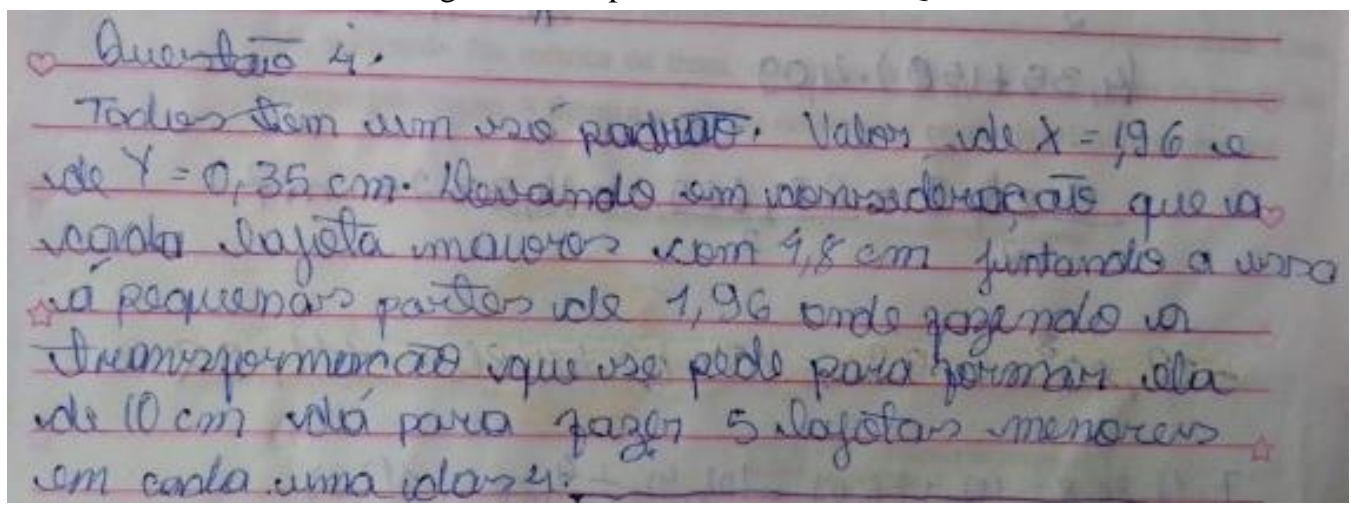

Fonte: Produção dos alunos (2019).

Questão 5. A entrada que dá acesso ao Santuário do Lima destaca-se por sua construção feita de pedras e por apresentar uma simetria que chama atenção, relembrando a época que foi construída e pelo trabalho desenvolvido com perfeição. São várias as relações que podem ser feitas com a matemática de acordo com o formato da construção apresentada. Quais as formas geométricas possíveis de visualizar na imagem abaixo? Ao considerar que a região em destaque terá que ser submetida a uma pintura, quantos $\mathrm{m}^{2}$ possui a região que será pintada? Utilize como auxílio algum instrumento de medição:

Figura 10 - Entrada do Santuário do Lima

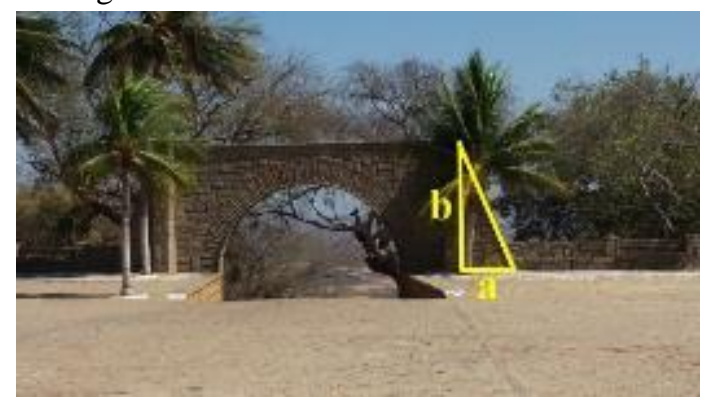

Fonte: Própria dos autores (2019).

As equipes apresentaram bom desempenho na resolução da Q5, na qual as respostas de todas as equipes foram consideradas como RS. Um exemplo de resposta nessa única categoria que ocorreu, pode ser visto na Figura 11. As equipes afirmaram que a região em destaque 
representava um triângulo retângulo, também certificaram que era possível visualizar formas geométricas como semicírculo. Considerando os resultados obtidos, percebeu-se que os alunos conseguiram fazer uso de conhecimentos de forma satisfatória, para responder a situação proposta, em que demonstraram compreensão sobre área de figuras geométricas planas. Diante dos valores estimados ( $a=1,73$ e $b=3,86$ ), calcularam a área da região que seria pintada, obtendo como resultado aproximado $3,33 \mathrm{~m}^{2}$.

Figura 11 - Resposta satisfatória a Q5

\begin{tabular}{|c|c|c|}
\hline 5. Sim, um & semicirculo it & truângulo \\
\hline rutângula. & 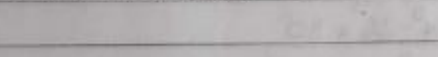 & \\
\hline & $2+18+0=8$ & \\
\hline a. $A=2 \cdot h$ & $a=\$, 73$ & \\
\hline 2 & $b: 3,86$ & \\
\hline$A=1,73,3,86$ & $\sin x=x$ & \\
\hline 2 & & \\
\hline$A=6,6718$ & $+30=5$ & \\
\hline 2 & trice & \\
\hline$A=3,3389$ & 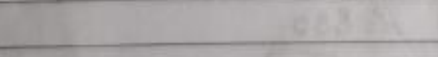 & \\
\hline$A=3,33 \mathrm{~m}^{2}$ & & \\
\hline
\end{tabular}

Fonte: produção dos alunos (2019).

Questão 6. Durante a observação das construções é possível mobilizar conhecimentos matemáticos escolares que podem ter sido utilizados desde a fundação, permitindo presenciar a aplicação da matemática em contextos cotidianos. Desse modo, podemos pensar na construção do Santuário de Nossa Senhora dos Impossíveis com seus pilares construídos de pedras que dão sustentação ao pavimento superior e a capela, fazendo ligação com conceitos geométricos. Eles estão distribuídos ao longo de um piso circular que, mais ao fundo, tem-se a capela do pavimento inferior. Analise a estrutura que dá sustentação ao pavimento superior. Considere o formato desses pilares, e diga qual figura geométrica eles se assemelham. Faça um desenho de um desses pilares e explique de que forma pode ser obtida a área dessa figura.

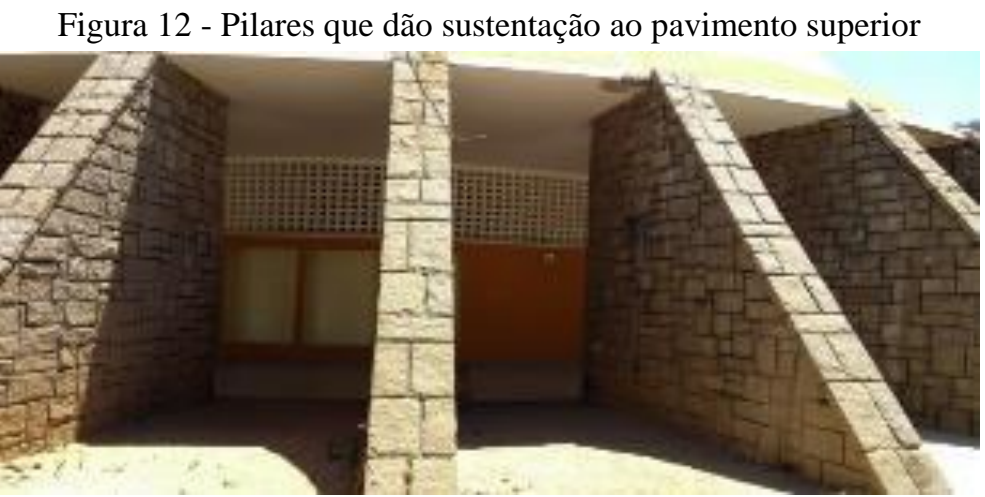

Fonte: Própria dos autores (2019). 
As respostas da Q6 foram distribuídas entre RPS e RI, de modo que quatro equipes apresentaram RPS e uma equipe RI. Baseados nos resultados obtidos, verificou-se que os alunos identificaram a semelhança da estrutura com um trapézio. Durante a resolução, após a identificação, os alunos fizeram as medições necessárias, utilizando trena e corda para auxiliar o processo. Em seguida, estimaram a área da região, como seguem os exemplos de respostas em cada categoria onde houve ocorrência:

Figura 13 - (a) Desenho de um trapézio representando um dos pilares e valores coletados; (b) RPS à Q6 (a)

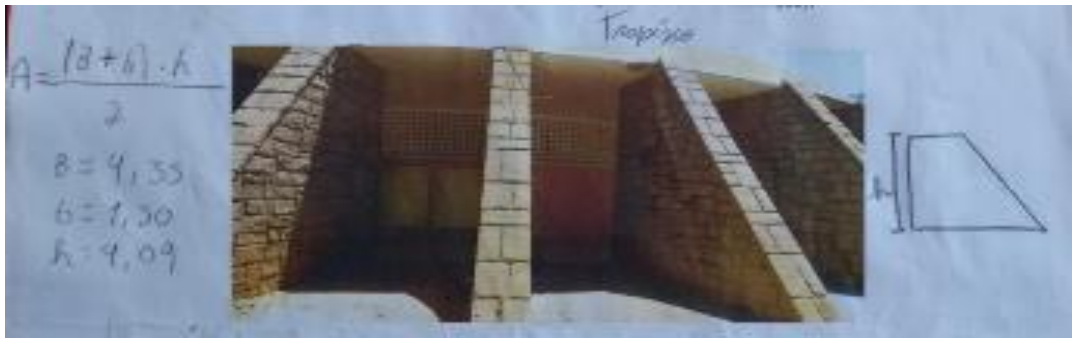

(b)

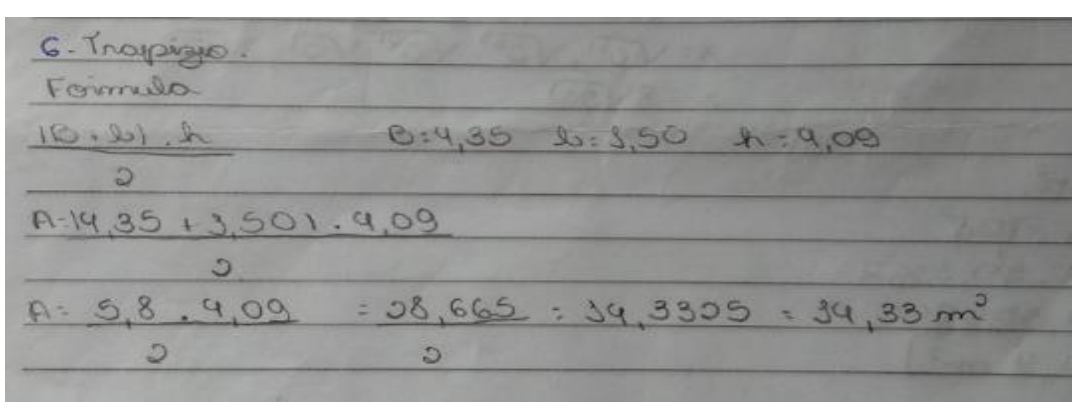

Fonte: Produção dos alunos (2019).

Com base no desenvolvimento da resposta disponibilizada por uma das equipes, é notório a compreensão dos alunos sobre os conteúdos abordados na Q6, pois conseguiram identificar qual forma geométrica representa a estrutura e fazer as medições correspondentes a base maior (B) e a base menor do trapézio (b) e altura (h), considerando um dos pilares. Porém, diante dos dados coletados, o resultado foi pouco satisfatório, pois durante a resolução os alunos efetuaram os cálculos de forma incorreta, obtendo um resultado diferente do que se esperava. Um exemplo de resposta considerada insatisfatória para a Q6 pode ser observado a seguir: 
Figura 14 - (a) Dados coletados da estrutura; (b) Dados utilizados incorretamente para resolução da Q6

(a)

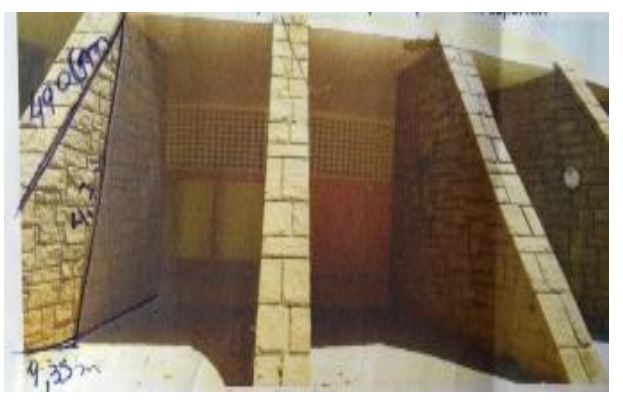

(b)

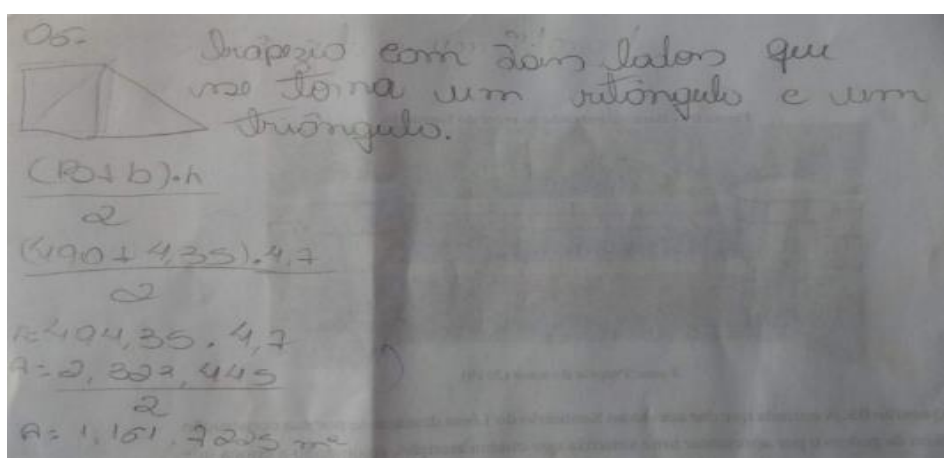

Fonte: Produção dos alunos (2019).

A figura nos mostra que as medidas coletadas na estrutura do pilar foram utilizadas de forma inadequada na equação $A=\frac{(B+b) \cdot h}{2}$, chegando a uma RI. Além de efetuar operação (soma) com unidades de medida diferentes.

Questão 7. Foi planejado o plantio de mudas de árvores nas duas laterais (ao longo do comprimento) da praça que cerca o Santuário do Lima, embora, ainda não se saiba o seu comprimento. Diante disso, qual a quantidade aproximada de mudas necessárias para o plantio, de forma que elas estejam distantes igualmente uma da outra em $9 \mathrm{~m}$, e contenha uma muda no início e final da praça? Assim, a Q7 apresentou um nível de dificuldade elevado, na qual o maior índice foram respostas pouco satisfatórias (duas equipes) e respostas insatisfatórias (duas equipes). Além de não apresentar resposta satisfatória e uma equipe deixou sem resposta. Para solucioná-la, as equipes precisavam medir o comprimento da praça que cerca o Santuário, em seguida, calcular a quantidade de mudas. Os alunos começaram a resolução ao estimar a medida aproximada do comprimento da praça, para isso, utilizaram uma corda que, de início mediram seu comprimento, encontrando 12,8 $\mathrm{m}$. Na Figura 15, dispomos exemplos de respostas em cada categoria onde houve ocorrência.

Os alunos concluíram que a praça tem aproximadamente $113,22 \mathrm{~m}$, como pode ser visualizado nos cálculos apresentados por uma equipe na Figura 15(a). Embora tenham estimado corretamente o comprimento da praça, ao calcular a quantidade de mudas que seriam plantadas, não interpretaram adequadamente a situação proposta. Eles apenas dividiram o valor encontrado do comprimento pela medida que elas estariam distantes igualmente uma da outra, de $9 \mathrm{~m}$. 
Figura 15 - (a) Resolução pouco satisfatória à Q7. (b) Resposta insatisfatória a Q7

(a)

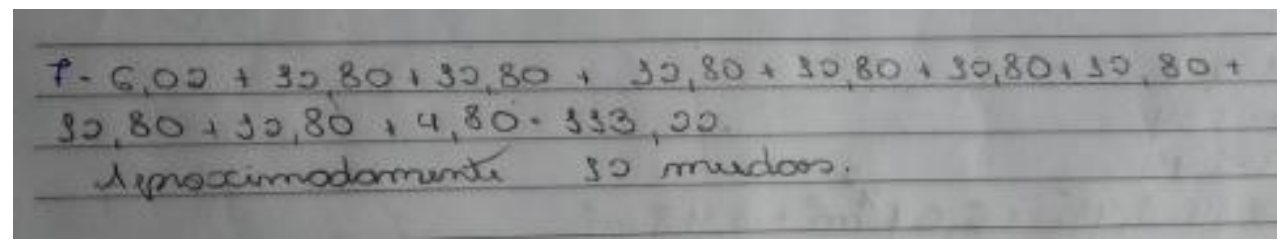

(b)

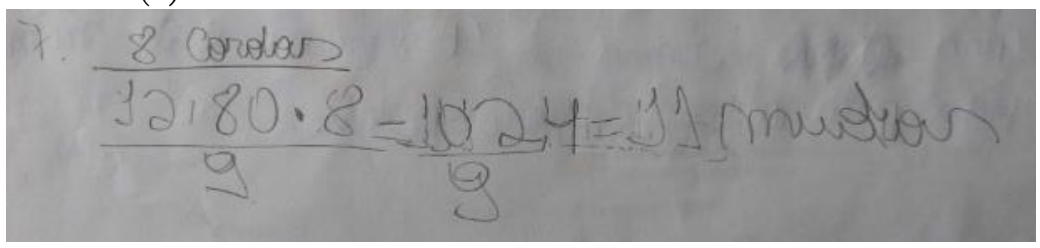

Fonte: Produção dos alunos (2019).

Além disso, não se apegaram ao fato de que tinha que haver uma muda no início e outra no final do Santuário, e serem plantadas ao longo das duas laterais. Ao invés de totalizar aproximadamente 12 mudas, seriam 13 mudas em cada lateral, sendo ao todo, 26 mudas nas duas laterais. Portanto, as resoluções que foram apresentadas dessa forma, foram consideradas RPS (Figura 15(a)). A solução apresentada na Figura 15(b) foi considerada como RI, pois os alunos consideraram apenas os espaços que foram medidos com a corda, não fazendo a medição dos que sobraram, aqueles que não puderam ser medidos com auxílio da corda que eram próximos a pousada e, assim, não estimaram corretamente o comprimento da praça que delimita o Santuário do Lima.

Desse modo, a atividade de campo proposta tratou de uma atividade prática que permitiu aos alunos a oportunidade de desmistificar a matemática como algo impossível de vivenciar e de aplicar, notando os conceitos geométricos aplicados em todo percurso que foi realizado no Santuário do Lima.

$\mathrm{Na}$ terceira etapa foi realizada a avaliação da aprendizagem pelo professor colaborador em sala de aula, com duração de $2 \mathrm{~h} / \mathrm{a}$. A atividade proposta foi composta por duas situaçõesproblemas, elaboras a partir de dados coletados no Santuário do Lima. Ao longo dessas situações, são abordados conteúdos geométricos como: comprimento de uma circunferência, área do círculo e de figuras geométricas planas. Enquanto no relatório solicitado, os alunos descreveram suas experiências durante a atividade de campo e de que forma ela foi contribuinte para sua aprendizagem.

Nesse contexto, os alunos que participaram da atividade de campo e não entregaram o relatório (12 alunos), e os que não participaram da atividade de campo (11 alunos), participaram 
da atividade aqui proposta, totalizando 23 alunos. Os únicos alunos que não participaram, foram aqueles que fizeram o relatório final da atividade de campo, sendo uma equipe com 4 alunos e uma com 3 alunos, implicando na participação direta dos demais alunos na resolução da atividade em sala, independente de terem participado ou não, da atividade de campo. Os alunos que não participaram da segunda etapa, puderam participar da terceira, pois o professor colaborador já havia trabalhado os conteúdos previamente durante a primeira etapa. Foi feita a avaliação da aprendizagem dos alunos, que permitiu verificar o desempenho dos que participaram da segunda etapa em comparação com os que não participaram, por meio dos resultados obtidos da atividade aqui proposta. Assim, foi possível observar as melhorias na aprendizagem dos alunos que participaram da atividade de campo.

Para análise dos dados, as respostas dos alunos foram classificadas de acordo com as categorias estabelecidas na seção anterior: Resposta Satisfatória - RS; Resposta Pouco Satisfatória - RPS; Resposta Insatisfatória - RI e Sem Resposta - SR. As duas SP's e os critérios utilizados estão no Quadro 04:

Quadro 4 - SP's e Critérios para as Respostas

\begin{tabular}{|c|l|}
\hline Questões & \multicolumn{1}{c|}{ Critérios } \\
\hline Q1 & $\begin{array}{l}\text { RS: se abordasse o comprimento da circunferência (exterior da capela), ao responder } \\
\text { quantos metros uma criança percorreria ao dar uma volta na parte externa da capela do } \\
\text { primeiro pavimento e a área da igreja desse mesmo pavimento (área do círculo); RPS: se } \\
\text { abordasse apenas uma tentativa de descrever o comprimento da circunferência (exterior da } \\
\text { capela do primeiro pavimento) ou uma tentativa de descrever a área da igreja desse } \\
\text { pavimento, onde durante a resolução as operações não sejam efetuadas corretamente; RI: } \\
\text { não abordasse o comprimento do exterior da capela do primeiro pavimento ou a área da } \\
\text { capela desse pavimento, de forma que os valores utilizados para o raio não estejam de } \\
\text { acordo com o que é solicitado em cada item da SP. }\end{array}$ \\
\hline Q2 & $\begin{array}{l}\text { RS: se abordasse a área aproximada de azulejo que deve ser colocada na parte interna do } \\
\text { escrito destacada na figura da Q2 (área do semicírculo + área do retângulo); RPS: se } \\
\text { abordasse apenas uma tentativa de descrever a área dessa região, de modo que não seja } \\
\text { calculado a área do semicírculo ou a área do retângulo e apresente o resultado; RI: não } \\
\text { abordasse os cálculos do desenvolvimento da Q2, apresentando apenas o resultados final ou } \\
\text { não abordasse corretamente a área aproximada de azulejo. }\end{array}$ \\
\hline
\end{tabular}
Fonte: Os autores (2020).

Questão 1. Visitando o Santuário, um turista pode perceber que a igreja é formada por dois pavimentos. O primeiro pavimento (térreo), apresenta formato cilíndrico e o pavimento superior ( $1^{\circ}$ andar) de um cone, quando visto de fora do Santuário, ambos divididos pela mesma base circular. Ao caminhar no primeiro pavimento, foi possível verificar que internamente a igreja possui $14,2 \mathrm{~m}$ de diâmetro e externamente possui $15,7 \mathrm{~m}$. A figura a seguir apresenta uma ilustração da estrutura descrita anteriormente.

a) Dessa forma, quantos metros percorre uma criança que der uma volta na parte externa da igreja? b) Qual a área da igreja existente no primeiro pavimento? 
Figura 16 - Representação do piso do primeiro pavimento

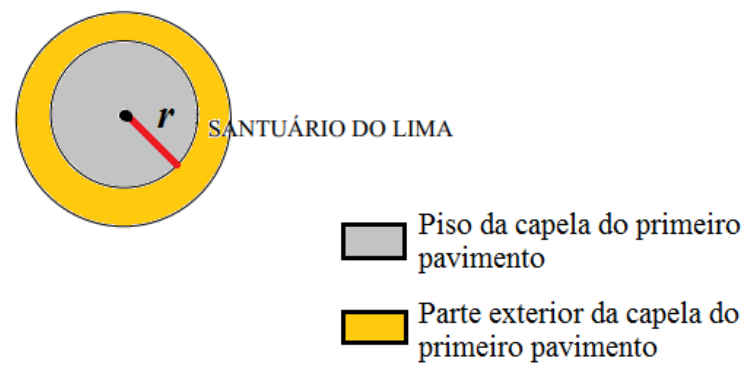

Fonte: Própria dos autores (2019).

Grande parte dos alunos desenvolveram de forma satisfatória o item "a", apresentando corretamente o comprimento da circunferência, ou seja, quantos metros uma criança iria percorrer, ao dar uma volta na parte externa da igreja, enquanto o índice de alunos que responderam de forma insatisfatória foi baixo. A Figura 17 apresenta a distribuição das respostas dos alunos para o item "a” da Q1.

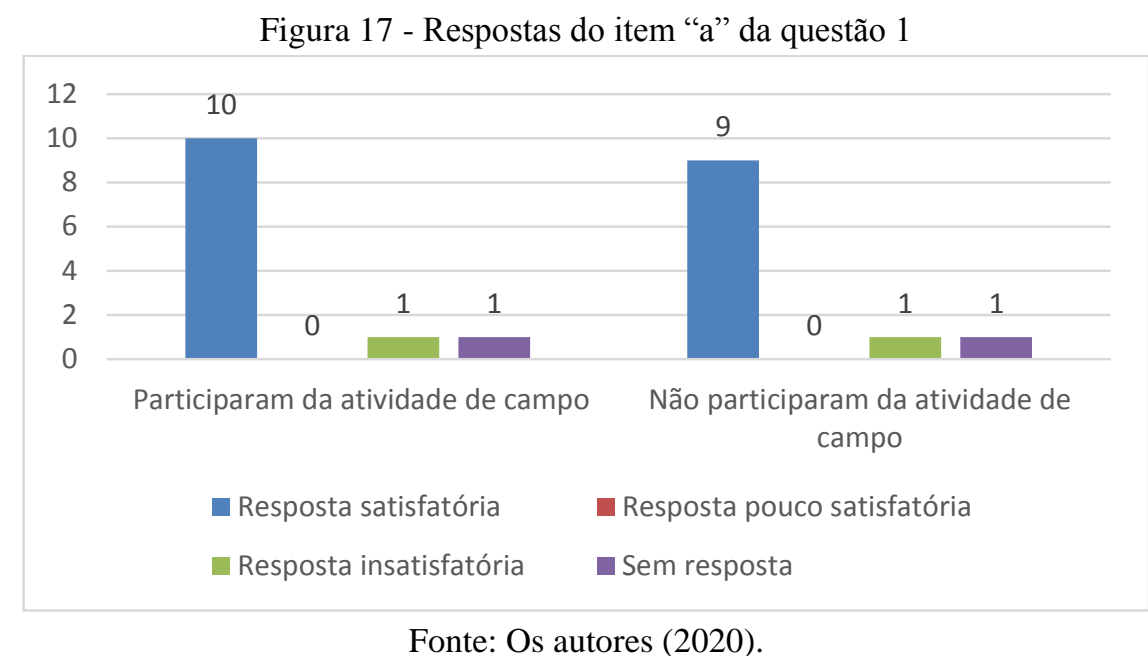

Baseados nos resultados apresentados para o item "b", percebeu-se que o maior número de respostas satisfatórias pertenceu aos alunos que haviam participado anteriormente da atividade de campo, onde forneceram a área da igreja do primeiro pavimento corretamente. A Figura 18, a seguir, apresenta os resultados para a Q1 item "b". 
Figura 18 - Respostas do item "b” da questão 1

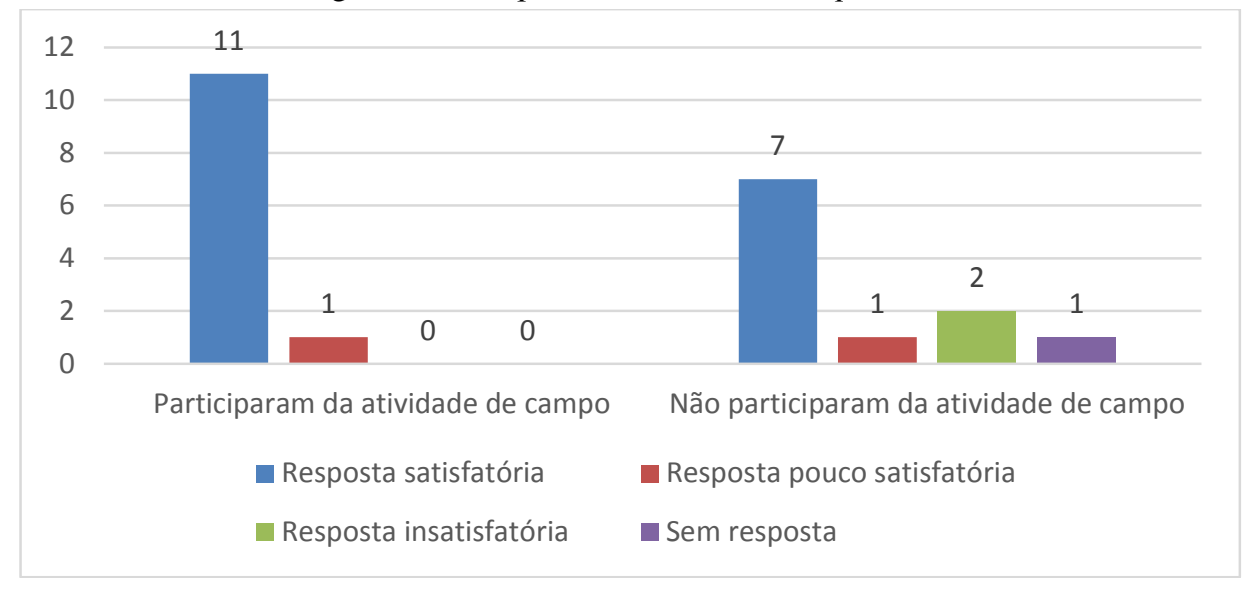

Fonte: Os autores (2020).

Questão 2. Ao longo da praça que cerca o Santuário do Lima, podemos encontrar diversos escritos que contam fatos históricos importantes do Santuário. Um exemplo desse escrito pode ser visto na figura a seguir:

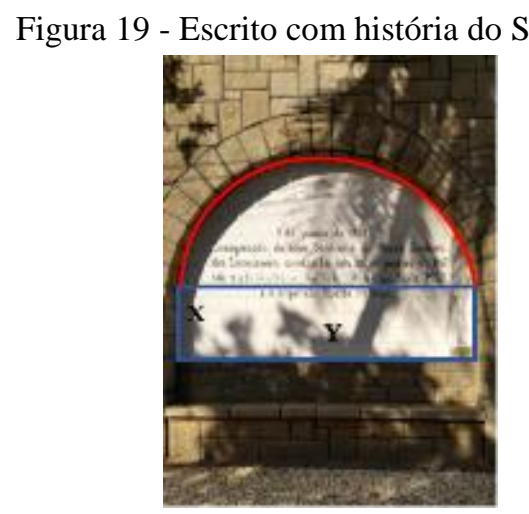

Fonte: Própria dos autores (2019).

Devido ao tempo de construção, uma restauração deverá ser realizada na parte interna (em cor branca) de cada escrito, onde será colocada novos azulejos. Qual a área aproximada que devem ser colocados azulejos? (Considere: $\mathrm{x}=0,35 \mathrm{~m}$ e $\mathrm{y}=2,9 \mathrm{~m}$ ).

Com base nos resultados apresentados pelos alunos, ficou visível que o maior número de RS foi desenvolvido pelos alunos que tinham participado da atividade de campo, além de apresentarem apenas uma RPS. Enquanto os alunos que não participaram, apresentaram suas respostas distribuídas entre RS e RI. As RS mostraram desenvolvimento adequado ao que era solicitado, deixando claro os passos de resolução que foram seguidos até encontrar a solução. Retratam a área aproximada que deve ser colocada azulejo na parte interna do escrito, efetuando a soma da área do semicírculo com a área do retângulo. A distribuição das respostas apresentadas pelos alunos para a Q2 pode ser visualizada na figura abaixo. 
Figura 20 - Respostas apresentadas para a questão 2

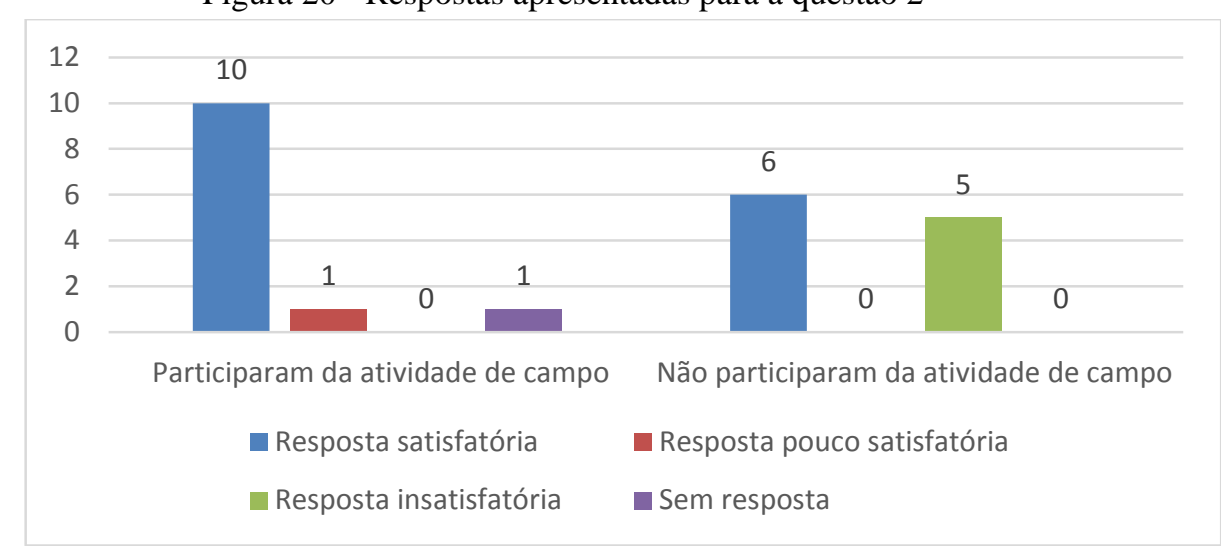

Fonte: Os autores (2020).

Os alunos que participaram da atividade de campo, quando resolveram a atividade em sala, deixaram visíveis sua compreensão e entendimento do que era solicitado através das resoluções apresentadas. Assim, apresentavam sentido e iam de acordo com os questionamentos, possibilitando a compreensão do passo a passo, utilizado durante a resolução e solução encontrada, além de possuir organização de ideias e respostas claras.

\section{CONSIDERAÇões FinaIs}

Este artigo apresenta a pesquisa desenvolvida e seus resultados obtidos, que foi embasada numa proposta de ensino que pode ser realizada durante aulas de matemática, podendo possibilitar a produção do conhecimento. O objetivo geral do nosso trabalho foi amparado na realização de uma atividade de campo para observar e identificar conceitos geométricos presentes nas edificações do Santuário do Lima, implementada pela resolução de situações-problemas. A partir das observações realizadas no local, os alunos puderam identificar e, consequentemente, compreender os conceitos abstraídos em sala de aula. Com isso, a atividade de campo e as situações-problemas mostram que é possível sanar dificuldades, reforçar conteúdos, até então já vistos, como também abre um leque de oportunidades para a aprendizagem de novos conhecimentos.

Portanto, entendemos que ministrar conteúdos, utilizando a atividade de campo em conjunto com resolução de situações-problemas, nos possibilita fornecer aos nossos alunos uma atividade prática, que facilita a compreensão dos conteúdos estudados. Além disso, proporciona o enriquecimento do ensino de geometria, no qual atribuem sentindo e importância aos seus conceitos, corroborando com a minimização das dificuldades enfrentadas diante desses conceitos. Cria a possibilidade de os alunos perceberem a matemática como uma disciplina que 
possui significado, além de aguçar a visualização dos conteúdos em aplicações que estão presentes além da sala de aula.

Concluímos que a utilização da atividade de campo agregada a resolução de situaçõesproblemas como metodologias para o ensino de conceitos geométricos, mostram-se como alternativas viáveis para o ensino de matemática.

\section{REFERÊNCIAS}

ARAÚJO, Denise Lino de. O que é (e como faz) sequência didática? Entrepalavras, v. 3, n. 1, p. 322-334, maio 2013. Disponível em:

http://www.entrepalavras.ufc.br/revista/index.php/Revista/article/view/148/181.\#. Acesso em: 29 jul. 2020.

BRASIL. Secretaria de Educação Fundamental. Parâmetros Curriculares Nacionais: Terceiro e Quarto Ciclo do Ensino Fundamental. Matemática. Brasília: MEC/SEF, 1998.

BOGDAN, Robert; BIKLEN, Sari. Investigação qualitativa em educação: uma introdução à teoria e aos métodos. Porto: Porto Editora, 1994.

CARBONELL, Jaume. A aventura de inovar: a mudança na escola. Porto Alegre: Artmed, 2002. (Coleção Inovação Pedagógica).

CARDOZO, Dionei; MENEGHELLI, Juliana; POSSAMAI, Janaína Poffo. Concepções dos professores de matemática quanto a utilização de exercícios, situações contextualizadas e problemas. Amazônia: Revista de Educação em Ciências e Matemáticas, v. 14, n. 31, p. 73 87, nov. 2018. Disponível em:

https://periodicos.ufpa.br/index.php/revistaamazonia/article/view/5701/5001. Acesso em: 15 mar. 2019.

CARVALHO, Dione Lucchesi de. Metodologia do ensino da matemática. 4. ed. São Paulo: Cortez, 2011.

DANTE, Luiz Roberto. Didática da Resolução de Problemas de matemática. São Paulo: Ática, 1989.

D’ AMBROSIO, Beatriz Silva. Como ensinar matemática hoje? Temas e Debates. SBEM. Brasília, ano 2, n. 2, p. 15-19, 1989.

DE FRUTOS, José Antonio. et al. Sendas ecológicas: un recurso didáctico para el conocimiento del entorno. Madrid: Editorial CCS, 1996.

ECHEVERRÍA, María Del Puy Pérez; POZO, Juan Ignacio. Aprender a Resolver Problemas e Resolver Problemas para Aprender. In: POZO, Juan Ignacio (Org.). A solução de problemas: Aprender a resolver, resolver para aprender. Porto Alegre: Artmed, 1998. p. 1342.

ELLIOTT, John. Action research for educational change. Milton Keynes: Open University, Press, 2004. 
HANSEN, Karem Susan. Metodologias de Ensino da Educação Ambiental no Âmbito da Educação Infantil. Ciência e Educação, ano 11, n. 43, 2013.

SOUZA, Joamir Roberto de; PATARO, Patricia Rosana Moreno. Vontade de saber matemática. 3. ed. São Paulo: FTD, 2015. (9ªno)

THIOLLENT, Michel. Metodologia da pesquisa-ação. 18. ed. São Paulo: Cortez, 2011.

VIVEIRO, Alessandra Aparecida; DINIZ, Renato Eugênio da Silva. As atividades de campo no ensino de ciências: reflexões a partir das perspectivas de um grupo de professores. In: NARDI, Roberto. (org). Ensino de ciências e matemática I: temas sobre a formação de professores. São Paulo: Cultura Acadêmica, 2009, p. 27-42. Disponível em:

http://books.scielo.org/id/g5q2h/pdf/nardi-9788579830044-03.pdf. Acessado em: 20 jan. 2020.

XAVIER, Odiva Silva; FERNANDES, Rosana César de Arruda. A Aula em Espaços NãoConvencionais. In: VEIGA, Ilma Passos Alencastro. Aula: Gênese, Dimensões, Princípios e Práticas. Campinas: Papirus Editora, 2008.

Recebido em: 25 de junho de 2020.

Aprovado em: 6 de agosto de 2020. 